\title{
A Phase Variation Event That Activates Conjugation Functions Encoded by the Enterococcus faecalis Plasmid pAD1
}

\author{
LINDA T. PONTIUS* AND DON B. Clewell ${ }^{*} \uparrow$ \\ *Department of Microbiology and Immunology. School of Medicine, and $\dagger$ Department of Biologic and Materials \\ Sciences, School of Dentistry, The University of Michigan, Ann Arbor, Michigan 48109
}

Received April 15, 1991; revised August 12, 1991

\begin{abstract}
Enterococcus faecalis cells carrying the conjugative plasmid pAD1 undergo several related changes when induced by the sex pheromone CAD1. Included are the production of novel surface proteins, the formation of cellular aggregates in broth cultures, the ability to transfer the plasmid at high frequency in broth matings, and the change from a soft to a "dry" colony morphology. Spontaneous, constitutively dry colony (Dry ${ }^{c}$ ) variants of $E$. faecalis (pAD1) were found to arise at a frequency of $10^{-4}-10^{-2}$. Dry ${ }^{c}$ phase variants constitutively expressed aggregation and plasmid transfer functions typically expressed only under cAD1-inducing conditions. Reversion of Dry ${ }^{c}$ variants to a cAD1-inducible phenotype (Dry ${ }^{+}$) occurred at a similar frequency. Tn 917-lac mutagenesis of regions of pAD1 previously shown to be involved in plasmid transfer revealed that in Dry ${ }^{+}$cells these regions were transcribed only when the inducer, cAD1, was present. In Dryc variants the regions were transcribed constitutively. A pAD1 miniplasmid containing determinants regulating $\mathrm{CAD} 1$ inducible plasmid transfer and a $\mathrm{CAD} 1$-inducible $l a c Z$ transcriptional fusion displayed phase variation in LacZ expression at a rate similar to the $\mathrm{Dry}^{+} / \mathrm{Dry}^{\mathrm{c}}$ phase variation. These results suggest that the site of mutation(s) resulting in the Dry ${ }^{\mathrm{c}}$ phenotype is within the regulation-related region of pAD1. Complementation tests showed that this region, when supplied in trans, complemented the Dry ${ }^{c}$ phenotype. Phase variation affecting mating functions represents an alternative (pheromone independent) method of regulating pAD1 transfer. (c) 1991 Acadermic Press, Inc.
\end{abstract}

pADl is a $60-\mathrm{kb}$ conjugative plasmid originally found in Enterococcus faecalis DS16 (Tomich et al., 1979). Dissemination of the plasmid is of clinical interest due to a hemolysin-bacteriocin determinant which may be a significant virulence factor (Ike et al., 1984, 1987). Like a number of other conjugative plasmids found in $E$. faecalis, transfer functions are induced by a sex pheromone excreted by potential recipients (reviewed in Clewell and Weaver, 1989). The transfer functions, in this case, are specifically induced by the small peptide, cAD1 (Mori et al., 1984).

Cells carrying pAD1 undergo a number of changes when stimulated by cAD 1 , including production of several novel surface proteins. Recent studies have indicated at least one of these proteins is plasmid encoded and corresponds to a cellular adhesin called aggrega- tion substance (Galli, et al., 1989, 1990). Production of the latter allows pAD1-containing cells to coaggregate with $E$. faecalis cells which do not contain pAD1 (i.e., recipients). Cellular clumping is readily observed when pAD1-containing cells are grown in broth in the presence of synthetic CAD1 or culture filtrate from cells which produce cADl. In a related phenomenon pADI-containing cells grown on solid media, which normally give rise to colonies that are dull and soft or fluid in consistency, characteristically give rise to bright, fracturable colonies when cAD1 is present (Weaver and Clewell, 1988).

In addition to inducing expression of aggregation substance, cAD 1 also induces the expression of genes required for plasmid DNA transfer (Clewell and Brown, 1980; Ehrenfeld and Clewell, 1987; this study). $E$. faecalis (pAD1) cells that are preinduced 
with CAD1 are capable of transferring the plasmid at high frequency in short broth matings (e.g., $10 \mathrm{~min}$ ) (Ike and Clewell, 1984). After receiving a copy of pAD1, endogenous cAD1 production by the recipient is shut down, although pheromones specific for other plasmids continue to be produced. A plasmid-encoded competitive inhibitor of cAD1, designated iAD1, is produced (Ike et al., 1983; Mori et al., 1986; Clewell et al., 1990) which acts to prevent induction of transfer functions if $\mathrm{CAD} 1$ levels are low.

Previous studies have shown that approximately half of pAD1 encodes products necessary for the mating response. Structural genes are believed to be coded for within regions $F$, $\mathrm{G}$, and H (Ehrenfeld and Clewell, 1987; see Fig. 1). Aggregation functions are encoded within the F region (Ehrenfeld and Clcwell, 1987; Galli et al., 1990), while the $G$ and $H$ regions appear to encode functions required for stabilization of mating aggregates and DNA transfer (Ehrenfeld and Clewell, 1987). Plasmid determinants responsible for regulating expression of transfer and aggregation have been localized to a 6-kb segment of the plasmid referred to as the regulatory region (Fig. 1). Areas within the regulatory region have been characterized by $\operatorname{Tn} 917$ and Tn917-lac mutagenesis (Ike and Clewell, 1984; Ehrenfeld and Clewell, 1987; Weaver and Clewell, 1988). The product of $\operatorname{traB}$ is believed to be involved in the shutdown of cAD1 production (Weaver and Clewell, 1990, 1991). The traA product acts to repress expression of aggregation and transfer functions when CAD1 is not present and is thought to play a role in pheromone sensing (Weaver and Clewell, 1988; Clewell and Weaver, 1989). Insertion mutations within either of these regions derepresses expression of aggregation and transfer functions. $C$ region product(s) is believed to play a role in pheromone sensing and possibly in CADl shutdown. $\mathrm{C}$ region mutants are phenotypically variable but all have elevated levels of $\mathrm{iAD} 1$ expression in an E. faecalis OG1X host background. This characteristic is hypothesized to be due to the inability of OGIX cells contain- ing $C$ region mutants to bind $\mathrm{A} A \mathrm{D} 1$ (Weaver and Clewell, 1990). traB, traA, and the $C$ region are constitutively transcribed (Weaver and Clewell, 1988). The E region is transcribed only in the presence of pheromone (Weaver and Clewell, 1988) and is thought to encode product(s) which act as positive regulators of proteins needed for aggregation and transfer (Weaver and Clewell, 1988). In addition, the gene encoding $\mathrm{iAD} 1$, the competitive inhibitor of $\mathrm{CAD} 1$, maps within the regulatory region (Clewell et al., 1990).

In the present study we have characterized a class of spontaneous mutants of $E$. faecalis (pAD1) which constitutively express cellular aggregation and plasmid transfer functions. The mutation(s) occurred at a frequency higher than would be expected for normal spontaneous mutation, and reversion was found to occur at approximately the same frequency as the forward mutation. This phase variation phenomenon was found to be related to a heritable change in pAD1, and evidence is presented suggesting the mutation(s) responsible occur within a portion of the pAD1 transfer regulatory region. Potential sites for the mutations responsible for phase variation within the regulatory region are discussed as well as implications of regulation of transfer via phase variation on the dissemination of pAD1.

\section{MATERIALS AND METHODS}

Bacterial strains and plasmids. All bacterial strains and plasmids used in this study are listed in Table 1. E. faecalis OGIX was used as a host strain unless otherwise noted. pAM714, a pAD I::Tn917 derivative that exhibits normal conjugation, was used instead of pAD1 in conjugation experiments because of the ease of selection for $\mathrm{Em}^{\mathrm{r}}$. The dry colony $\left(\right.$ Dry $\left.{ }^{c}\right)$ variants pAM714SW2 and pAM714SW3 were derived in separate experiments. OG1RF(pAM211) was used as the donor strain in surface exclusion experiments.

pAM7701 is a recombinant consisting of the shuttle vector pAM401 (Wirth et al., 
TABLE 1

STRAINS AND PLASMIDS

\begin{tabular}{|c|c|c|}
\hline Strain or plasmid & Relevant characteristics & Ref. \\
\hline \multicolumn{3}{|l|}{ Strains } \\
\hline \multicolumn{3}{|l|}{ E. faecalis } \\
\hline OG1X & str & lke et al. (1983) \\
\hline OGIRF & riffus & Oliver et al. (1977) \\
\hline FA2-2 & riffus & Clewell et al. (1982) \\
\hline DS16 & tet erm & Tomich et al. (1979) \\
\hline $\mathrm{JH} 2-2$ & riffus $\operatorname{Rec}+$ & Jacob and Hobbs (1974) \\
\hline UV202 & rif fus $\operatorname{Rec}^{-}$(derived from $\mathrm{JH} 2-2$ ) & Yagi and Clewell (1980) \\
\hline \multicolumn{3}{|c|}{ 年 } \\
\hline DH5 $\alpha$ & $\begin{array}{l}\mathrm{F}^{-} 80 \mathrm{~d} l a c Z \Delta \mathrm{M} 15 \Delta(\text { lacZYA-argF) U169 recAl end A1 } \\
\quad h s d \mathrm{R} 17\left(\mathrm{r}_{\mathbf{k}}^{-}, \mathrm{m}_{\mathbf{k}}^{+}\right) \text {supE44 } \lambda^{-} \text {thi-1 gyrA }\end{array}$ & Bethesda Research Labs \\
\hline \multicolumn{3}{|c|}{ का } \\
\hline pAD1 & Hemolysin-bacteriocin, $\mathrm{Agg}^{+}, \mathrm{Tra}^{+}$. & Tomich et al. (1979) \\
\hline pAM211 & pAD1::Tn916, tet, $\mathrm{Agg}^{+}, \mathrm{Tra}^{+}$ & Gawron-Burke and Clewell (1982) \\
\hline pAM401 & E. coli-E. faecalis shuttle vector, cat & Wirth et al. (1986) \\
\hline pAM714 & pAD1::Tn917, erm $, \mathrm{Agg}^{+}, \mathrm{Tra}^{+}$ & Ike et al. (1983) \\
\hline pAM7 14SW2 & Dry $^{c}$ phase variant of pAM714. & This study \\
\hline pAM714SW3 & Dry ${ }^{c}$ phase variant of pAM714. & This study \\
\hline pAM714SW2R & Dry $^{+}$revertant of pAM714SW2. & This study \\
\hline pAM2011E & $\begin{array}{l}\text { Miniplasmid derived from pAM2011, erm, } \mathrm{Agg}^{-} \text {, Tra } \\
\text { (see Results, Fig. 3B). }\end{array}$ & Weaver and Clewell (1989) \\
\hline pAM2120 & $\begin{array}{l}\text { pADI with a Tn917-lac insert in } t \text { raA. Constitutive for } \\
\text { aggregation and transfer. }\end{array}$ & Weaver and Clewell (1988) \\
\hline pAM7016 & $\begin{array}{l}\text { pADl with a Tn917-lac insert in the mapping at } 15.0 \mathrm{~kb} \\
\text { on the pADI map, } \mathrm{Agg}^{+}, \mathrm{Tra}^{+} \text {. }\end{array}$ & This study \\
\hline pAM7227 & $\begin{array}{l}\text { pAD1 with a Tn917-lac insert in the I region, } \mathrm{Agg}^{+} \text {, } \\
\mathrm{Tra}^{+} \text {(see Table 4). }\end{array}$ & This study \\
\hline pAM7245 & $\begin{array}{l}\text { pAD1 with a } \operatorname{Tn} 917-\text { lac insert in the I region, } \mathrm{Agg}^{+} \text {, } \\
\operatorname{Tra}^{+} \text {(see Table 4). }\end{array}$ & This study \\
\hline pAM7500 & $\begin{array}{l}\text { Amp (The HindIII fragment of pAD1 spanning 17.2- } \\
22.2 \text { on the pAD1 map, inserted into the HindIII site } \\
\text { of pBluescript (Stratagene). }\end{array}$ & $\begin{array}{l}\text { (Pontius and Clewell, manuscript } \\
\text { in preparation) }\end{array}$ \\
\hline pAM7607 & Dry $^{c}$ variant of pAM7016, $\left(\mathrm{Tra}^{+}\right)$ & This study \\
\hline pAM7608 & Dry $^{c}$ variant of pAM $7245,\left(\mathrm{Tra}^{+}\right)$ & This study \\
\hline pAM7609 & Dry $^{\complement}$ variant of pAM $7227,\left(\mathrm{Tra}^{+}\right)$ & This study \\
\hline pAM7701 & $\begin{array}{l}\text { pAM401 with an insert of pAD1 DNA [including } \operatorname{traA} \text {, } \\
\text { iad, the } \mathrm{C} \text { region and a portion of } t \text { raB and the } \mathrm{E} \\
\text { region, } \mathrm{Tra}^{-}, \mathrm{Agg}^{-} \text {(see Materials and Methods)]. }\end{array}$ & This study \\
\hline
\end{tabular}

Note. $\mathrm{Agg}^{+}$, capable of aggregation in response to $\mathrm{CAD1}$; $\mathrm{Agg}^{-}$, incapable of aggregation in response to $\mathrm{CAD} 1$; $\mathrm{Tra}^{+}$, transfer proficient; $\mathrm{Tra}^{-}$, incapable of self-transfer.

1986) and a portion of the pAD1 regulatory region, specifically the HindIII fragment spanning $17.2-22.2 \mathrm{~kb}$ on the pADl map, which includes a portion of the E region, iad, $\operatorname{traA}, \operatorname{tra} B$, and the $C$ region (Weaver and Clewell, 1989; Clewell et al., 1990) (see Fig. 3). pAM7701 was constructed by first digesting pAM7500 (pBluescript containing the
pAD1 HindIII fragment of interest (Pontius, manuscript in preparation) with $\mathrm{BamHI}$ and Sall. These fragments were cloned into BamHI/SalI-digested pAM401 using standard cloning procedures (Maniatus et al., 1982). The resulting ligation mixture was used to transform Escherichia coli strain DH $5 \alpha$, and $\mathrm{Cm}^{\mathrm{r}}$ isolates were selected. Iso- 
lates were then screened for $\mathrm{Tet}^{\mathrm{s}}$ and Amp. Plasmid DNA was collected (by the method of Ish-Horowitz and Burke, 1981) from selected transformants and restriction analyses were performed to confirm that the recombinant contained the desired insert.

Reagents. Antibiotics were generally used in the following concentrations: ampicillin, $100 \mu \mathrm{g} / \mathrm{ml}$; tetracycline, $20 \mu \mathrm{g} / \mathrm{ml}$; rifampin, $25 \mu \mathrm{g} / \mathrm{ml}$; fusidic acid, $25 \mu \mathrm{g} / \mathrm{ml}$; streptomycin, $1000 \mu \mathrm{g} / \mathrm{ml}$; chloramphenicol, $25 \mu \mathrm{g} / \mathrm{ml}$; and erythromycin, $10 \mu \mathrm{g} / \mathrm{ml}$. In the case of $E$. faecalis transformations, an erythromycin concentration of $2 \mu \mathrm{g} / \mathrm{ml}$ and a chloramphenicol concentration of $15 \mu \mathrm{g} / \mathrm{ml}$ were used. Media for culture of E. faecalis strains were THB (Todd-Hewitt Broth, Difco Laboratories, Detroit, MI) or N2GT [Nutrient Broth No. 2, Oxoid Ltd., London, England), supplemented with $0.2 \%$ glucose and $0.1 \mathrm{M}$ Tris-HCl (pH 7.5)]. Media for culture of $E$. coli was LB (Davis et al., 1980). When solid media was required $1.5 \%$ agar (Difco) was added. Synthetic cADI was generally used at a concentration of $40 \mathrm{ng} / \mathrm{ml}$ and 5-bromo-4chloro-3-indolyl- $\beta$-D-galactopyranoside (Xgal) ${ }^{1}$ (Sigma Chemical Co., St. Louis, MO) was used at a concentration of 100-200 $\mu \mathrm{g} /$ ml. Restriction enzymes and T4 DNA ligase were obtained from New England Biolabs (Beverly, MA) and were used under conditions recommended by the manufacturer.

Frequency of phase variation. Frequency of E. faecalis OG1X (pAD1) and OG1X (pAM714) phase variation was determined after suspending a single colony of each strain in N2GT broth with appropriate antibiotics, incubating overnight, and plating out dilutions of the overnight culture on solid media. Screening for variants was performed on the basis of colony morphology. The rate of variation of OG1X (pAM2011E) was determined by suspending a block of agar with one 36-hold colony in broth and immediately plating dilutions on solid media containing X-gal.

\footnotetext{
${ }^{1}$ Abbreviations used: $X$-gal, 5-bromo-4-chloro-3 indolyl- $\beta$-D-galactopyranoside; $C C$, counterclockwise.
}

This method allows calculation of rate of phase transition in variants/cfu/generation (Eisenstein, 1981). Screening was based on colony color after $36 \mathrm{~h}$. Values of frequency and rates of variation of $E$. faecalis cells given in Tables 2 and 5 should be viewed as approximations. While every effort was made to vortex cells vigorously prior to plating it is doubtful that cell chains or even cell aggregates were completely dispersed prior to plating.

Conjugation and transformation. Ten-minute broth matings were done as previously described (Ehrenfeld and Clewell, 1987). Nonconjugative introduction of plasmid DNA into OGIX was accomplished using a protoplast transformation procedure (Wirth et al., 1986). Transformation of $E$. coli was done as previously described (Gawron-Burke and Clewell, 1984). Transformation of strain UV202 was performed using a procedure developed for electroporation (Cruz-Rodz and Gilmore, 1990).

Surface exclusion experiments. Experiments were designed as previously described (Dunny et al., 1985). Overnight cultures of donors were diluted 1:10 in fresh N2GT with cADI and preincubated for $1 \mathrm{~h}$ at $37^{\circ} \mathrm{C}$. Overnight cultures of recipients were diluted in a like manner and preincubated in N2GT with or without cAD1. Following preincubation, a 15-min broth mating was performed. Transconjugants were selected on the basis of resistance to streptomycin $(1000 \mu \mathrm{g} / \mathrm{ml})$ and tetracycline $(10 \mu \mathrm{g} / \mathrm{ml})$.

iADl assays. iAD1 assays (Ike et al., 1983) were performed as previously described using E. faecalis DS16 as the responder strain. Twofold dilutions of each filtrate were tested for the ability to inhibit the clumping response of the responder strain in a solution containing cAD1. One unit of iAD1 activity is defined as the amount required to reduce a given cAD1 titer by half (lke et al., 1983). Culture filtrates were prepared when cultures reached late exponential growth phase (a reading of 90 using a Klett-Summerson colorimeter (Klett Manufacturing Co., Long Island City, NY), with a number 54 filter). 
Tn917-lac mutagenesis of pAD1. Tn917lac mutagenesis of pAD1 was accomplished using the delivery vector $p$ TV32Ts provided by P. Youngman (Perkins and Youngman, 1986; Youngman, 1987). Mutagenesis and mapping of transposon inserts was performed as previously described (Weaver and Clewell, 1988) in an E. faecalis host background. Mutants used in this study were selected randomly and on the basis of reduction in plasmid transfer efficiency, the inability to aggregate in response to $\mathrm{CAD} 1$, or cAD1-inducible production of $\beta$-galactosidase. To determine the latter, cells were placed on solid media containing X-gal with or without cAD1. Colony color was observed after 24 and $48 \mathrm{~h}$ incubation at $37^{\circ} \mathrm{C}$.

\section{RESULTS}

Aggregation characteristics of Dry variants. OGIX(pAD1) colonies typically appear dull and are soft or fluid in consistency when grown on solid media. If grown on solid media containing CAD1, colonies appear dry and fracturable (Weaver and Clewell, 1988). This cADl-inducible change in colony morphology is referred to here as Dry ${ }^{+}$. At a frequency higher than would be expected for normal spontaneous mutation constitutivcly bright, fracturable colonies, designated Dry $^{\mathrm{c}}$, were found. Dry ${ }^{\mathrm{c}}$ cells reverted back to wild-type $\left(\mathrm{Dry}^{+}\right)$-also at a relatively high frequency. The frequencies of variation observed between Dry ${ }^{+}$and Dry ${ }^{\mathrm{c}}$ states in experiments using OG1X(pAD1) and OG1X(pAM714) are given in Table 2. Both strains gave rise to Dry ${ }^{c}$ variants at a frequency of $10^{-4}-10^{-2}$. The frequency of reversion of Dry $^{c}$ variants to the Dry ${ }^{+}$phenotype was similar. Previous studies have linked a dry, fracturable colony morphology with the CAD1-inducible expression of cellular aggregation functions (Ike and Clewell, 1984; Weaver and Clewell, 1988). It was therefore of interest to determine whether the Dry ${ }^{+} \leftrightarrow$ Dry $^{c}$ phase variation affected expression of these aggregation factors. Indeed, when grown in broth, Dryc cells aggregated with an appear- ance similar to that of $\mathrm{Dry}^{+}$cells that were exposed to cAD1. Revertants of Dry ${ }^{c}$ variants showed the pheromone-inducible expression of aggregation factors typical of cells carrying wild-type pAD1. The appearance of four novel surface proteins has previously been correlated with pheromone-inducible aggregation in an OGIX E. faecalis background (Ehrenfeld and Clewcll, 1987; Weaver and Clewell, 1988). Western blot analysis showed that Dry ${ }^{c}$ variants constitutively produce these proteins, whereas Dry ${ }^{+}$ revertants produced these proteins only when grown in the presence of cAD1 (not shown).

Plasmid transfer characteristics of Dry ${ }^{c}$ variants. Previous studies (Clewell and Brown, 1980; Ehrenfeld and Clewell, 1987) showed that in addition to induction of aggregation, pheromone also induced functions required for DNA transfer. It was therefore of interest to determine whether phase variants were altered in expression of plasmid transfer functions or if the phenomenon was linked only to a change in cellular aggregation characteristics. OG1X(pAM714) and a Dryc variant of this strain were tested for the ability to transfer the plasmid in 10 -min broth matings. Normally, significant plasmid transfer in such matings occurs only when donors are preinduced with cAD1 (Ike and Clewell, 1984). As shown in Table 3, Dry ${ }^{\mathrm{c}}$ variants were found to transfer the plasmid efficiently, at a frequency at least 200 -fold higher than a Dry $^{+}$strain. A Dry ${ }^{+}$revertant of OG1X(pAM714SW2) that was tested for ability to transfer in 10-min broth matings showed no detectable transfer (transfer of $<10^{-7}-10^{-6}$ transconjugants/donor), which is typical of the wild-type phenotype [since induction by pheromone requires at least 20-30 min (Ike and Clewell, 1984)]. Dry ${ }^{+}$revertant plasmids transferred at wild-type levels (approximately $10^{-3}$ transconjugants/donor) in $1-\mathrm{h}$ broth matings, indicating a return to normal, cAD1-inducible, regulation of transfer function expression. Thus, expression of plasmid transfer functions, as well as cellular aggregation functions, are linked to phase variation. 
TABLE 2

Phase VARIATION FReQuenCy OF OG1X(pAD 1) AND OG $1 \mathrm{X}(\mathrm{pAM} 714)$

\begin{tabular}{lcccc}
\hline Plasmid & & & $\begin{array}{c}\text { Variant colonies/ } \\
\text { total colonies }\end{array}$ & Frequency \\
\hline \multirow{2}{*}{ pAD1 } & Phase transition & & & \\
& Dry $^{+} \rightarrow$ Dry $^{\mathrm{c}}$ & & & \\
& & Expt 1 & $9 / 7688$ & $1.2 \times 10^{-3}$ \\
pAM714 & Expt 2 & $6 / 3322$ & $1.8 \times 10^{-3}$ \\
& & Expt 3 & $1 / 3275$ & $3.1 \times 10^{-4}$ \\
& & Expt 1 & $1 / 6852$ & $1.5 \times 10^{-4}$ \\
pAD1 & Expt 2 & $169 / 2944$ & $5.7 \times 10^{-2}$ \\
& Dry $^{c} \rightarrow$ Dry $^{+}$ & & & $2.3 \times 10^{-2}$ \\
& & Expt 1 & $40 / 1715$ & $3.1 \times 10^{-2}$ \\
pAM714 & Expt 2 & $13 / 425$ & $9.4 \times 10^{-3}$ \\
& & Expt 3 & $33 / 3506$ & $7.3 \times 10^{-4}$ \\
& & Expt 1 & $3 / 4127$ & $3.3 \times 10^{-4}$ \\
\hline
\end{tabular}

Tn917-lac mutagenesis of pAD1. To gain additional evidence that pADl-encoded mating response genes in addition to aggregation factors are expressed under noninducing conditions by Dry ${ }^{\mathrm{c}}$ phase variants, Tn917-lac mutagenesis of pAD1 was undertaken, and several of the derivatives were tested for phase variation. The position of each Tn917lac insert obtained is shown in Fig. 2. Specific map positions and the orientation of the lac $Z$ fusion created by the insert relative to the pAD1 map are listed in Table 4.

In all cases where the orientation of the fusion was such that potential transcription of lac $Z$ could occur in a counterclockwise orientation (CC), relative to the pAD1 map shown in Fig. 2, pAD1::Tn917-lac mutants gave rise to blue colonies on X-gal media containing
cAD1 and white colonies on media devoid of the pheromone. When lac Z fusions were oriented in the opposite direction no transcription was detected on either medium. Thus, transcription could only be detected as occurring in a $\mathrm{CC}$ direction and only in the presence of cAD1. Interestingly, pheromone-inducible transcription was observed in the region counterclockwise to the H-region, now designated I, where associated phenotypes are not presently known. It was also observed that transcription levels, as judged qualitatively from the intensity of colony color on exposure to CAD1, appeared lower in the latter area compared to the $\mathrm{F}, \mathrm{G}$, or $\mathrm{H}$ regions.

In order to examine transcription at various insertion points, Dry ${ }^{c}$ variants of several of the newly generated Tn917-lac deriva-

TABLE 3

TRANSFER FREQUENCY OF DRY ${ }^{+}$AND DRY ${ }^{c}$ OGIX $(\mathrm{pAM} 714)^{a}$

\begin{tabular}{lcc}
\hline \multicolumn{1}{c}{ Plasmid } & \multicolumn{2}{c}{ Transfer frequency (in Transconjugants/donor) } \\
\cline { 2 - 3 } & 10 -min broth mating & 1 -h broth mating \\
\hline pAM714 $\left(\right.$ Dry $\left.^{+}\right)$ & $<5.0 \times 10^{-7}$ & $6.1 \times 10^{-3}$ \\
pAM714SW2 $\left(\right.$ Dry $\left.^{c}\right)$ & $4.7 \times 10^{-4}$ & $5.9 \times 10^{-3}$ \\
pAM714SW2R2 $\left(\text { Dry }^{+}\right)^{b}$ & $<5.0 \times 10^{-7}$ & $3.3 \times 10^{-3}$ \\
\hline
\end{tabular}

${ }^{a}$ Ten-minute and 1-h broth matings were performed between Dry ${ }^{+}$or Dry ${ }^{c}$ OG1X(pAM714) and FA2-2.

${ }^{b}$ pAM714SW2R2 is a Dry ${ }^{+}$revertant derived from pAM714SW2. 


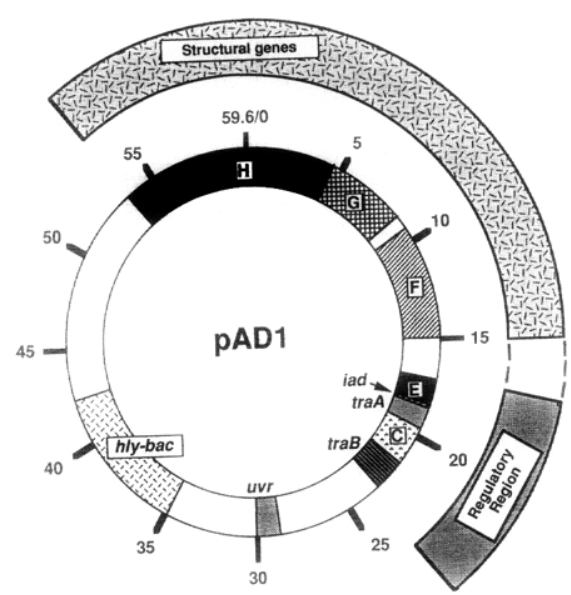

FIG. 1. Map of pAD1. Regions believed to encode the structural genes required for the mating response are labeled $F, G$, and $H$. The region responsible for regulating expression of the mating response is also indicated. It includes $t r a A, t r a B$, $i a d$, and the $C$ and $E$ regions. $h l y-b a c$ indicates the location of the hemolysin-bacteriocin determinant. $u v r$ indicates the position of an ultraviolet light resistance determinant.

tives were obtained. No $F$ region derivatives were tested; since unlike other Tn917-lac mutants obtained, these strains were incapable of aggregating in broth or expressing a dry colony morphology in response to cAD1 (data not shown) and should therefore be incapable of expressing a Dry phenotype. Strains tested included those Tn917-lac mutants with $\mathrm{cAD} 1$-inducible lac $Z$ fusions indicated by an asterisk in Fig. 2 .

Selected OG1X(pAD1::Tn917-lac) derivatives were plated on solid media, and phase variants of each strain were selected on the basis of a Dryc colony morphology. These arose at a frequency of $10^{-5}-10^{-3}$. The derivatives were then plated on media containing $\mathrm{X}$-gal but no cAD1. In each case the colonies that arose were blue. Thus, transcript(s) normally made only in the presence of pheromone were constitutively produced by Dry ${ }^{\mathrm{c}}$ variants. These results provide additional evidence indicating that expression of structural genes involved in the mating response, in addition to aggregation factors, are affected by phase variation.
Localization of DNA responsible for phase variation. Results indicating that both transfer and aggregation functions were constitutively expressed in Dryc variants led to the hypothesis that the mutation(s) responsible for phase variation occurred on pAD1, possibly within the regulatory region, rather than the chromosome of the host strain. It was not surprising then to find that when plasmid DNA was obtained from both a Dry variant of OG1X(pAM714) and a revertant strain and introduced into plasmidless strains of OG1X by protoplast transformation, transformants exhibited the phenotype of the strain from which the particular plasmid was isolated (not shown). Thus, phase variation is due to heritable changes in pADI DNA.

To determine if the mutations relating to phase variation were in the regulatory region of pAD1 (i.e., between 17.0 and $23.0 \mathrm{~kb}$ on the pAD1 map) a miniplasmid derivative, pAM2011E, was tested for phase variation (Weaver and Clewell, 1989) (depicted in Fig. 3B). The miniplasmid consists of a $15-\mathrm{kb}$ region of pAD1 DNA that includes the regulatory region. In addition, the miniplasmid carries a Tn917-lac insert that interrupts the $\mathrm{E}$ region, which is essential for positive regulation of the pheromone response. The lac $Z$ fusion created by the Tn917-lac insertion (Weaver and Clewell, 1989) normally produces LacZ only when cAD1 is present. Phase variation to the Dry ${ }^{\mathrm{c}}$ phenotype in

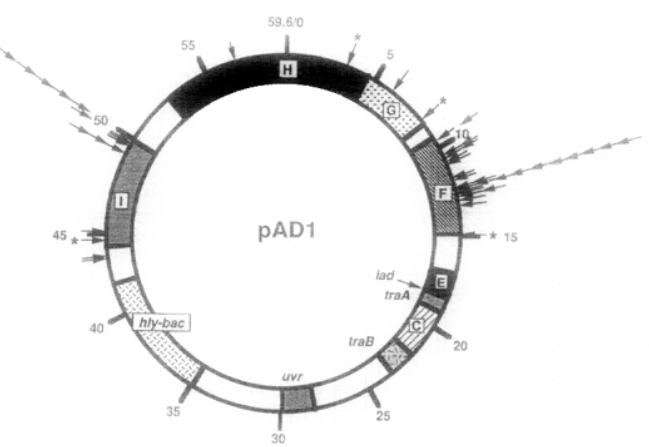

FIG. 2. Position of Tn9/7-lac inserts in pAD1. The arrows mark the position of inserts obtained and asterisks mark derivatives tested for phase variation. 
TABLE 4

POSITION OF Tn917-lac INSERTS IN pAD1 ${ }^{a}$

Inserts with lacZ fusions in a counterclockwise orientation ${ }^{b}$
pAM7241 (44.1), pAM7248 (44.4), pAM7245 (44.7), pAM7203 (48.9), pAM7219 (49.8), pAM7233 (49.8),
pAM7215 (50.0), pAM7227 (50.0), pAM7229 (50.0), pAM7214 (50.0), pAM7201 (50.0), pAM7137 (3.3),
pAM7142 (6.1), pAM7109 (8.6), pAM7131 (9.8), pAM7144 (9.8), pAM7136 (11.0), pAM7104 (11.1), pAM71 10
(11.1), pAM7044 (11.9), pAM7035 (12.5), pAM7020 (12.8), pAM7028 (12.8), pAM7021 (12.9), pAM7001
(12.9), pAM7022 (12.9), pAM7085 (12.9), pAM7040 (12.9), pAM7014 (12.9), pAM7033 (12.9), pAM7042
(12.9), pAM7061 (12.9), pAM7018 (12.9), pAM7025 (13.2), pAM7030(13.2), pAM7004 (13.4), pAM7016 (15.0)

Inserts with $l a c Z$ fusions in a clockwise orientation ${ }^{c}$ pAM7275 (45.1), pAM7243 (48.9), pAM7225 (48.9), pAM7261 (49.2), pAM7226 (49.5), pAM7114 (57.0), pAM7 102 (11.0), pAM7027 (12.1), pAM7034 (12.4), pAM7024 (13.0), pAM7049 (13.1), pAM7077 (13.6)

\footnotetext{
${ }^{a}$ Map positions of Tn917-lac inserts in pAD1 correspond to those shown on the pAD1 map (Fig. 2).

${ }^{b}$ Indicates potential transcription across the lac $Z$ fusion would occur in a counterclockwise direction in relation to the pAD1 map (Fig. 2).

${ }^{c}$ Indicates potential transcription across the lacZ fusion would occur in a clockwise direction in relation to the pADI map (Fig. 2).
}

OG1X(PAM2011E) could not be observed because pAD1 genes necessary for expression of aggregation and plasmid transfer functions had been deleted. OG1X(pAM2011E) was tested for phase variation by observing changes in colony color when the strain was plated on solid media containing $\mathrm{X}$-gal. The results are shown in Table 5. Blue colony variants occurred at a frequency of approximately $10^{-4}-10^{-3}$, and white colony revertants appeared at a similar frequency. An estimate of the actual rate of phase transition, found to be $10^{-5}-10^{-4} / \mathrm{CFU}$ per generation, could be made in this case (see Materials and Methods) because, unlike pAD1 or pAM714, pAM2011E is incapable of self-transfer during the experiment. When white colony revertants were streaked on plates containing $\mathrm{X}$-gal and cAD1, the colonies that arose were blue indicating the revertants had returned to normal pheromone-inducible regulation of the lac $Z$ fusion.

Protoplast transformation experiments were performed to determine whether the

A. PAD1 Regulatory Region.

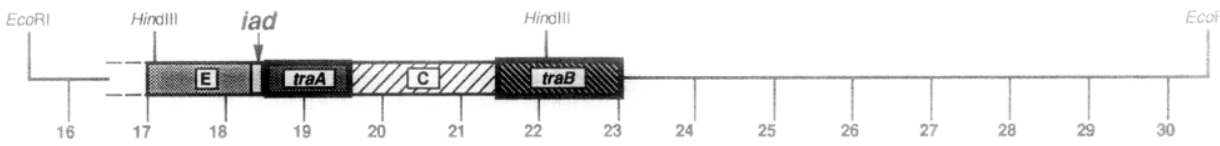

B. PAM2011E.

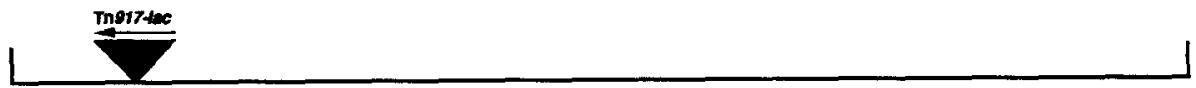

C. PAM7701.

FIG. 3. (A) The regulatory region of pAD1. (B) Corresponding DNA present on the miniplasmid pAM2011E (Weaver and Clewell, 1989) with the position of a Tn917-lac insert indicated. (C) Portion of pADI included in the recombinant pAM7701. 
TABLE 5

Rate of Phase Variation of OG1X(pAM2011E) ${ }^{a}$

\begin{tabular}{lcc}
\hline & \multicolumn{2}{c}{$\begin{array}{c}\text { Rate of phase variation } \\
\text { (Variants/CFU/generation) }\end{array}$} \\
\cline { 2 - 3 } & White $\rightarrow$ Blue & Blue $\rightarrow$ White \\
\hline Expt 1 & $1.8 \times 10^{-3}$ & $2.7 \times 10^{-4}$ \\
Expt 2 & $6.2 \times 10^{-5}$ & $1.6 \times 10^{-4}$ \\
Expt 3 & $1.1 \times 10^{-4}$ & $1.5 \times 10^{-4}$ \\
\hline
\end{tabular}

${ }^{a}$ Colonics $36 \mathrm{~h}$ old wcre suspended and immediately plated on solid media (THB with agar) containing 100 $\mu \mathrm{g} / \mathrm{ml} \mathrm{X}$-gal and appropriate antibiotics. Colony color determinations were made after $36 \mathrm{~h}$ incubation at $37^{\circ} \mathrm{C}$. Frequencies are reported in variants/CFU/generation; number of generations varied from 23 to 28 .

phase transition observed was plasmid directed. Plasmid DNA was isolated from blue colony variants, white colony revertants, as well as the original OG1X(pAM2011E). When pAM2011E was used to transform OG1X, 114 transformants were obtained. On X-gal-containing media 105 of these transformants gave rise to white colonies while 9 gave rise to blue colonies. When plasmid DNA from a blue colony variant was used, 38 of 39 transformants gave rise to blue colonies. When plasmid DNA from a white colony revertant was used to transform OG1X, 321 of 326 transformant colonies were white; the remaining 5 were blue. All transformants gave rise to blue colonies when plated on media containing X-gal and cAD1. Since the majority of transformants were true to parental type, it was concluded that the observed phase change of OG1X(pAM$2011 \mathrm{E}$ ) is plasmid directed.

Because the frequency of white $\leftrightarrow$ blue phase variation of pAM2011E is similar to that for Dry $^{+} \leftrightarrow$ Dry $^{c}$ phase variation of OG1X(pAD1) and because in each case genes necessary for expression of plasmidregulated aggregation and transfer functions are affected by phase variation, we believe the two phenomena are related. The data imply that the mutations responsible for phase variation occur within the region of the plasmid previously shown to regulate the pheromone response-between 17.0 and $23.0 \mathrm{~kb}$ on the pAD1 map (Fig. 1 and Fig. 3A).

Complementation analyses. To further examine the nature of the mutation(s) responsible for phase variation a portion of the regulatory region of pAD1 was cloned and tested for the ability to complement the Dryc phenotype in trans. pAD1 DNA corresponding to the region $17.2-22.2 \mathrm{~kb}$ on the pAD1 map (Fig. 1 and Fig. 3C) was inserted into an appropriate shuttle vector (pAM401) and the recombinant plasmid, pAM7701, was introduced via electroporation into the $\operatorname{Rec}^{-} E$. faecalis strain UV202. A control strain, UV202(pAM401), was also constructed. OG1X strains harboring pAM714, pAM7227, pAM7245, or pAM7016 and Dry ${ }^{\mathrm{c}}$ variants of each strain were then used as donors in matings with the recipients UV202(pAM401) and UV202(pAM7701). Transconjugants were observed for colony morphology and, when appropriate, for colony color on media containing X-gal. Transconjugants resulting from matings with the recipient UV202(pAM401) were true to the original donor phenotype. pAD1 derivatives, including those from Dry ${ }^{c}$ donors, when introduced into UV202(pAM7701), however, showed a soft colony morphology. Those carrying LacZ fusions gave rise to white colonies on plates containing X-gal. Thus, the Dryc phenotype was complemented (or suppressed) in trans by a product(s) from the portion of the $\mathrm{pAD} 1$ regulatory rcgion present on the recombinant plasmid pAM7701 [17.2-22.2 kb (Fig. 3C)].

Surface exclusion characteristics of Dry ${ }^{c}$ variants and a traA mutant. Previous reports showed that surface exclusion functions of pAD1 (Clewell and Brown, 1980) and pCF10 (another conjugative, pheromone-inducible $E$. faecalis plasmid) were pheromone inducible. In the case of $\mathrm{pCF} 10$ regulation of surface exclusion was not necessarily linked to regulation of transfer and aggregation functions; a transfer constitutive, aggregation constitutive mutant of pCF 10 did not constitutively express surface exclusion functions 
TABLE 6

EXPRESSION OF SURFACE (ENTRY) EXCLUSION FUNCTIONS BY DRY ${ }^{c}$ VARIANTS AND A traA MUTANT OF pAD1 ${ }^{a}$

\begin{tabular}{|c|c|c|c|c|c|}
\hline \multirow[t]{2}{*}{$\begin{array}{l}\text { Plasmid content } \\
\text { of the recipient }\end{array}$} & & \multicolumn{3}{|c|}{ Transconjugants/recipient } & \multirow[t]{2}{*}{$P$ Value $^{d}$} \\
\hline & & & $-\mathrm{cAD}^{b}$ & $+\mathrm{CAD}^{c}{ }^{c}$ & \\
\hline \multirow[t]{6}{*}{ pAM714 } & Expt 1 & & $6.4 \times 10^{-4}$ & $9.9 \times 10^{-6}$ & \\
\hline & Expt 2 & & $7.7 \times 10^{-4}$ & $5.0 \times 10^{-7}$ & \\
\hline & Expt 3 & & $7.6 \times 10^{-4}$ & $5.8 \times 10^{-6}$ & \\
\hline & Expt 4 & & $1.7 \times 10^{-4}$ & $4.4 \times 10^{-5}$ & \\
\hline & Expt 5 & & $2.0 \times 10^{-4}$ & $3.1 \times 10^{-5}$ & \\
\hline & & Mcan & $5.1 \times 10^{-4}$ & $1.8 \times 10^{-5}$ & $<0.005$ \\
\hline \multirow[t]{5}{*}{ pAM2120 } & Expt 1 & & $5.6 \times 10^{-6}$ & $2.6 \times 10^{-5}$ & \\
\hline & Expt 2 & & $4.5 \times 10^{-6}$ & $5.3 \times 10^{-6}$ & \\
\hline & Expt 3 & & $5.8 \times 10^{-6}$ & $5.9 \times 10^{-5}$ & \\
\hline & Expt 5 & & $2.7 \times 10^{-5}$ & $9.4 \times 10^{-6}$ & \\
\hline & & Mean & $1.1 \times 10^{-5}$ & $2.5 \times 10^{-5}$ & N.S. \\
\hline \multirow[t]{4}{*}{ pAM714SW2 } & Expt 3 & & $7.1 \times 10^{-4}$ & $5.0 \times 10^{-5}$ & \\
\hline & Expt 4 & & $1.2 \times 10^{-3}$ & $2.5 \times 10^{-4}$ & \\
\hline & Expt 5 & & $1.2 \times 10^{-4}$ & $1.4 \times 10^{-5}$ & \\
\hline & & Mean & $6.8 \times 10^{-4}$ & $1.0 \times 10^{-4}$ & $0.05<P<0.1^{e}$ \\
\hline \multirow[t]{4}{*}{ pAM714SW3 } & Expt 1 & & $3.2 \times 10^{-4}$ & $1.7 \times 10^{-5}$ & \\
\hline & Expt 2 & & $1.5 \times 10^{-5}$ & $5.7 \times 10^{-5}$ & \\
\hline & Expt 3 & & $8.4 \times 10^{-1}$ & $1.0 \times 10^{-5}$ & \\
\hline & & Mean & $3.9 \times 10^{-4}$ & $2.8 \times 10^{-5}$ & $0.1<P<0.375^{e}$ \\
\hline \multicolumn{6}{|c|}{$\begin{array}{l}\left.{ }^{a} \text { Experiments were performed as described under Materials and Methods. The donor strain, OGIRF(pAM } 111\right) \text {, } \\
\text { was preincubated for } 1 \mathrm{~h} \text { in N2GT broth containing cAD1, prior to matings. Matings were for } 15 \mathrm{~min} \text {. } \\
{ }^{b} \text { Recipients were preincubated for } 1 \mathrm{~h} \text { in } \mathrm{N} 2 \mathrm{GT} \text { broth prior to matings. } \\
{ }^{c} \text { Recipients were preincubated for } 1 \mathrm{~h} \text { in } \mathrm{N} 2 \mathrm{G} l \text { broth with cADl prior to matings. } \\
{ }^{d} P \text { values are for } t \text { test (unpaired) comparisons for each isolate with vs without cAD1. Transformation of the data } \\
\text { and use of geometric means rather than arithmetic means does not change results obtained substantially. N.S., not } \\
\text { significant. } \\
{ }^{e} \text { If the data for pAM714SW2 and pAM714SW3 are combined the } P<0.025 \text {. }\end{array}$} \\
\hline
\end{tabular}

(Dunny et al., 1985). Phenotypic observations and results of complementation tests suggested that mutations within the $\operatorname{traA}$ locus (which encodes a negative regulator of aggregation and transfer gene expression) might be responsible for phase variation. If so, expression of surface exclusion functions of traA mutants and Dry variants should be the same under both inducing and noninducing conditions. Experiments were performed to determine whether this was the case, and the results are shown in Table 6. OG1X (pAM714), used here as the control or "wildtype" recipient, consistently exhibited a significant $(P \leqslant 0.005)$ reduction in uptake of donor plasmid DNA when it (the recipient) had been preincubated with cAD1 prior to mating. OG1X(pAM2120), containing pAD1 with a Tn917-lac insert in traA, was reduced in plasmid entry under both inducing and noninducing conditions at the approximate level of induced OGIX(pAM714). The Dry ${ }^{c}$ variants resembled that of wild type-with a reduction in uptake only if preincubated with $\mathrm{CAD} 1(P \leqslant 0.025$ for the combined data from pAM714SW2 and pAM714SW3). Thus, while surface exclusion functions of the $\operatorname{traA}$ insertion mutant was constitutively expressed, this was not the case for the Dry variants.

Comparative restriction analysis. Phase variation phenomena are known in some cases to involve DNA rearrangements (e.g., inversions, insertions/excisions, etc), and 
comparative restriction fragment analyses proved useful in identifying the region of DNA affected (Abraham et al., 1985; Marrs et al., 1988; Komano et al., 1986, 1990; Bartlett et al., 1988; Bartlett and Silverman, 1989). With the hope of gaining insight into the nature and location of the mutations responsible for phase variation, wild-type pAD1 and plasmid DNA from OG1X(pAD1) Dryc variants, as well as pAM2011E and plasmid from blue colony variants of OG1X(pAM2011E), were analyzed using a number of restriction enzymes. Restriction enzymes used included $A l u \mathrm{I}, B a m \mathrm{HI}, E c o \mathrm{RI}$, HaeIII, HincII, HindIII, HpaI, HpaII, MseI, PvuII, RsaI, SalI, Sau3A, and TaqI. Digests were compared using both agarose and polyacrylamide gel electrophoresis. No differences in restriction patterns were detected between plasmid from variant cells and plasmid obtained from cells with nonvariant phenotype.

cADI and iADI levels of Dry ${ }^{c}$ variants. Previous studies indicated that the relative level of $\mathrm{CAD} 1$ to $\mathrm{iAD} 1$ is critical in determining whether plasmid transfer functions are expressed (Ike et al., 1983; Mori et al., 1986; Ehrenfeld and Clewell, 1987). One easily testable hypothesis to explain the observed phase variation was that Dryc phase variants expressed less $\mathrm{iAD} 1$, and/or that cAD1 was bcing produced at levels that would cause selfinduction. Either of these occurrences would be detected as an apparent decrease in iAD1 production in an iAD1 microtiter assay. However, when iAD1 levels of OG1X $E$. faecalis strains containing variant plasmids were tested, they were found to be the same as for OG1X containing wild-type pAD1.

Phase variation in a Rec ${ }^{-}$host. To determine if homologous recombination played a role in phase variation, UV202(pAM714) and UV202(pAM7016) were examined and compared to $\mathrm{Rec}^{+}$isogenic control strains JH2-2(pAM714) and JH2-2(pAM7016). UV202(pAM7016) was found to change to the Dryc phenotype at a frequency of $9.2 \times$ $10^{-6}$ in one experiment. No mutants were detected (a frequency of $<10^{-6}$ ) in two other experiments. In a JH2-2 background pAM7016 changed to the Dryc phenotype at an average frequency of $3.5 \times 10^{-6}$ in three experiments, but no mutants were detected (a frequency of $<10^{-6}$ ) in two additional experiments. Results for UV202(pAM714) and JH2-2(pAM714) were similar. The data imply that phase variation is Rec-independent; however, it appears to occur at a lower frequency in the $\mathrm{JH} 2-2$ host (the $\mathrm{Rec}^{+}$parental strain of UV202) compared to the nonisogenic OG1X.

\section{DISCUSSION}

In this study we have found that OG1X(pAD1) undergoes a heritable, reversible, phenotypic change from $\mathrm{Dry}^{+}$to $\mathrm{Dry}^{\mathrm{c}}$ colony morphology at a frequency of $10^{-4}$ $10^{-2}$. In addition to a change in colony morphology Dry ${ }^{c}$ variants constitutively express aggregation and plasmid transfer functions that are normally expressed only in the presence of cAD1. Restriction fragment polymorphism analysis with a number of restriction enzymes have revealed no detectable changes in restriction patterns. These results make it appear unlikely that insertion and excision of an IS element, or a gross DNA rearrangement is responsible for the changes observed during phase variation. Results indicate that the mutations responsible for phase variation occur within the regulatory region of pAD1. Sequence analysis of a portion of the regulatory region (Clewell et al., 1990; Pontius and Clewell, manuscript in preparation) reveals the presence of large numbers of direct and indirect repeats where small insertion/deletion events resulting in frameshift mutations might occur (reviewed in Levinson and Gutman, 1987; Ripley, 1990).

The Dry ${ }^{c}$ phenotype could be complemented in trans with a portion of the regulatory region from pAD1. The construct tested contained portions of the $\mathrm{E}$ region and $t \mathrm{raB}$, as well as $i a d$, the $C$ region, and $\operatorname{traA}$. $\operatorname{tr} a B$ is believed to produce products necessary for cAD1 shutdown; traB mutants have a "ringed" colony morphology (Weaver and 
Clewell, 1988) which is not typical of Dry ${ }^{c}$ phase variants, making it seem unlikely that the mutations responsible for phase variation occur within $\operatorname{traB}$. It is also unlikely that an alteration of the $\mathrm{E}$ region, which encodes determinant(s) necessary for positive regulation of the pheromone response, is responsible for phase variation; $\mathrm{E}$ region product in trans would not be expected to complement (cause apparent repression of) the Dryc phenotype. The level of the inhibitor, iAD1, produced by variants was identical to wild type, so mutations affecting iad are not responsible for phase variation.

Changes affecting the negatively acting $\operatorname{traA}$ product would predictably result in many of the phenotypic changes observed during phase variation to the Dry ${ }^{c}$ state. However, surface exclusion functions of a $t r a A$ mutant are fully derepressed while those of Dry ${ }^{c}$ variants are not; the latter appear to remain inducible. Additional data (not shown) indicate $\mathrm{pAD} 1$ transfers from $\mathrm{Dry}^{\mathrm{c}}$ variants during 10-min broth matings at an even higher frequency if the donors are preinduced with pheromone. cAD1-inducible transfer is not characteristic of pAD1::Tn917-traA and pAD1::Tn917-lac-traA mutants (Ike and Clewell, 1984; Weaver and Clewell, 1988). These results suggest that TraA may be partially functional in Dry ${ }^{c}$ variants. A mutation resulting in a reduced activity or level of TraA might result in a Dry ${ }^{\mathrm{c}}$ phenotype.

A mutation affecting $\mathrm{C}$ region product alone is unlikely to be responsible for phase variation. All $C$ region insertion derivatives obtained to date express elevated levels of iAD1 in an OG1X E. faecalis host background, a characteristic which is not typical of Dry ${ }^{c}$ phase variants. Tn917-lac insertions within the $\mathrm{C}$ region mapping near traA show a partial derepression of aggregation and transfer functions (Weaver and Clewell, 1988). These findings suggest the possibility that efficient production of TraA might be affected by mutations within the $\mathrm{C}$ region. Thus, the results obtained to date suggest that the mutations responsible for phase variation directly or indirectly affect TraA production. Comparative nucleotide sequencing analyses (underway) should reveal the precise location of the responsible mutations.

Phase variation provides an alternative mechanism for regulating pAD1 fertility functions and allows plasmid transfer to occur in the absence of pheromone. pAD1 could then be introduced into recipient strains that do not excrete CAD1 thereby extending its host range. Another possible role for phase variation stems from the recent observation by Galli et al. (1990) that the pAD1 aggregation substance (the product of asal) contains two tetra-amino acid motifs that have been shown in other systems to contribute to binding to eukaryotic cells. Since pAD1 is already believed to contribute to virulence as a result of its hemolysin-related determinant (Ike et al., 1984, 1987), the possibility that phase variants constitutively expressing aggregation substance might more readily colonize human/animal tissue is worthy of consideration.

\section{ACKNOWLEDGMENTS}

We thank F. An, K. Tanimoto, M. Sulavik, Y. Su, and $K$. Weaver for helpful discussion. This study was supported by Public Health Service Grants GM33956 and AI10318 from the National Institutes of Health.

\section{REFERENCES}

Abraham, J. M., Freitag, C. S., Clements, J. R., and EISENSTEIN, B. I. (1985). An invertible element of DNA controls phase variation of type 1 fimbriae of Escherichia coli. Proc. Natl. Acad. Sci. USA 82, 57245727.

Bartlett, D. H., and Silverman, M. (1989). Nucleotide sequence of IS492, a novel insertion sequence causing variation in extracellular polysaccharide production in the marine bacterium Pseudomonas atlantica. J. Bacteriol. 171, 1763-1766.

BARTKETT, D. H., WRIGHT, M. E., AND SILVERMan, M. (1988). Variable expression of extracellular polysaccharide in the marine bacterium Pseudomonas atlantica is controlled by genome rearrangement. Proc. Natl. Acad. Sci. USA 85, 3923-3927.

Clewell, D. B., AND BRown, B. L. (1980). Sex pheromone cAD1 in Streptococcus faecalis: Induction of a function related to plasmid transfer. I. Bacteriol. 143, 1063-1065. 
Clewell, D. B., Pontius, L. T., AN, F. Y., Ike, Y., SuzUKI, A., AND NakaYama, J. (1990). Nucleotide sequence of the sex pheromone inhibitor (iAD1) determinant of Enterococcus faecalis conjugative plasmid pAD1. Plasmid 24, 156-161.

Clewell, D. B., Tomich, P. K., Gawron-Burke, M. C., Franke, A. E., YAGi, Y., AND AN, F. Y. (1982). Mapping of Streptococcus faecalis plasmids pADI and pAD2 and studies relating to transposition of $\operatorname{Tn} 917$. J. Bacteriol. 152, 1220-1230.

Clewell, D. B., AND Weaver, K. E. (1989). Sex pheromones and plasmid transfer in Enterococcus faecalis. Plasmid 21, 175-184.

Cruz-Rodz, A. L., AND Gilmore, M. S. (1990). High efficiency introduction of plasmid DNA into glycine treated Enterococcus faecalis by electroporation. $\mathrm{Mol}$. Gen. Genet. 224, 152-154.

Davis, R. W., Botstein, D., AND Roth, J. R. (1980). "Advanced Bacterial Genetics." Cold Spring Harbor Laboratory, Cold Spring Harbor, NY.

DunNY, G. M., Zimmeraman, D. L., AND ToRTORELLO, M. L. (1985). Induction of surface exclusion (entry exclusion) by Streptococcus faecalis sex pheromones: Use of monoclonal antibodies to identify an inducible surface antigen involved in the exclusion process. Proc. Natl. Acad. Sci. USA 82, 8582-8586.

EISENSTEIN, B. I. (1981). Phase variation of type $1 \mathrm{fim}-$ briae in Escherichia coli is under transcriptional control. Science 214, 337-339.

EHRENFELd, E. E., AND Clewell, D. B. (1987). Transfer functions of the Streptococcus faecalis plasmid pAD1: Organization of plasmid DNA encoding response to sex pheromone. .J. Bacteriol. 169, 3473-3481.

Galli, D. Lottspeich, F., AND WiRTh, R. (1990). Sequence analysis of Enterococcus faecalis aggregation substance encoded by the sex pheromone plasmid pADI. Mol. Microbiol. 4, 895-904.

Galli, D., Wirth, R., AND WANNER, G. (1989). Identification of aggregation substances of Enterococcus faecalis cells after induction by sex pheromones. Arch. Microbiol. 151, 486-490.

Gawron-Burke, C., ANd Clewell, D. B. (1982). A transposon in Streptococcus faecalis with fertility properties. Nature (London) 300, 281-284.

Gawron-Burke, C., ANd Clewell, D. B. (1984). Regeneration of insertionally inactivated Streptococcal DNA fragments after excision of transposon $\mathrm{Tn} 916$ in Escherichia coli: Strategy for targeting and cloning of genes from gram-positive bacteria. J. Bacteriol. 159, 214-221.

IKE, Y., AND CLEWELL, D. B. (1984). Genetic analysis of the pADI pheromone response in Streptococcus faecalis, using transposon $\mathrm{Tn} 917$ as an insertional mutagen. J. Bacteriol. 158, 777-783.

IKe, Y., Craig, R. A., White, B. A., YAGi, Y., AND Clewell, D. B. (1983). Modification of Streptococcus faecalis sex pheromones after acquisition of plasmid DNA. Proc. Natl. Acad. Sci. USA 80, 5369-5373.

Ike, Y., Hashimoto, H., and Clewell, D. B. (1984). Hemolysin of Streptococcus faecalis subspecies zymogenes contributes to virulence in mice. Infect. Immun. 45, 528-530.

IKe, Y., Hashimoto, H., AND Clewell, D. B. (1987). High incidence of hemolysin production by Enterococcus faecalis strains associated with human parenteral infections. J. Clin. Microbiol. 25, 1524-1528.

ISH-HorowITZ, I. D., AND BURKE, J. K. (1981). Rapid and efficient cosmid cloning. Nucleic Acids Res. 9, 2989-2998.

JACOB, A. E., AND HoBBS, S. J. (1974). Conjugal transfer of plasmid-borne multiple antibiotic resistance in Streptococcus faecalis var, zymogenes. J. Bacteriol. 117, 360-372.

Komano, T., Funayama, N., Kim, S., and Nisioka, T. (1990). Transfer region of Incl1 plasmid R64 and role of shufflon in R64 transfer. J. Bacteriol. 172, 22302235.

Komano, T., Kubo, A., Kayanuma, T., Furuichi, T., AND NisioKA, T. (1986). Highly mobile DNA segment of Incl $\alpha$ plasmid R64: a clustered inversion region. $J$. Bacteriol. 165, 94-100.

LeVInSON, G., AND Gutman, G. A. (1987). Slippedstrand mispairing: A major mechanism for DNA sequence evolution. Mol. Biol. Evol. 4, 203-221.

Maniatus, T., Fritsch, E. F., AND Sambrook, J. (1982). "Molecular Cloning: A Laboratory Manual." Cold Spring Harbor Laboratory, Cold Spring Harbor, NY.

Marrs, C. F., ReuHL, W. W., SchoOlnik, G. K., AND FALKOW, S. (1988). Pilin gene phase variation of Moraxella bovis is caused by an inversion of the pilin gene. J. Bacteriol. 170, 3032-3039.

Mori, M., ISOGaI, A., SaKagami, Y., Fujino, M., KITAda, C., Clewell, D. B., AND SuzuKI, A. (1986). Isolation and structure of the Streptococcus faecalis sex pheromone inhibitor, iADl, that is excreted by the donor strain harboring plasmid pAD1. Agric. Biol. Chem. 50, 539-541.

Mori, M., Sakagami, Y., Narita, M., Isogai, A., FUjino, M., Kitada, C., Craig, R., Clewell, D. B., AND SUZUKI, A. (1984). Isolation and structure of the bacterial sex pheromone, cAD1, that induces plasmid transfer in Streptococcus faecalis. FEBS Lett. 178, 97100.

Oliver, D. R., Brown, B. L., AND Clewell, D. B. (1977). Analysis of plasmid deoxyribonucleic acid in a cariogenic strain of Streptococcus faecalis: An approach to identifying genetic determinants on cryptic plasmids. J. Bacteriol. 130, 759-765.

Perkins, J. B., ANd Youngman, P. J. (1986). Construction and properties of Tn917-lac, a transposon derivative that mediates transcriptional gene fusions in $B a$ cillus subtilis. Proc. Natl. Acad. Sci. USA 83, 140-144. 
RIPLEY, L. S. (1990). Frameshift mutation: Determinants of specificity. Annu. Rev. Genet. 24, 189-213.

TOMich, P. K., AN, F. Y., DAMLE, S. P., AND Clewell, D. B. (1979). Plasmid-related transmissibility and multiple drug resistance in Streptococcus faecalis subspecies zymogenes strain DS16. Antimicrob. Agents Chemother. 15, 828-830.

WEAVER, K. E., AND CleWELL, D. B. (1988). Regulation of the pAD1 sex pheromone response in Enterococcus faecalis: Construction and characterization of lac $\mathrm{Z}$ transcriptional fusions in a key control region of the plasmid. J. Bacteriol. 170, 4343-4352.

Weaver, K. E., and Clewell, D. B. (1989). Construction of Enterococcus faecalis pAD1 mini-plasmids: Identification of a minimal pheromone response regulatory region and evaluation of a novel pheromone-dependent growth inhibition. Plasmid 22, 106-119.

WEAVER, K. E., AND CleWELL, D. B. (1990). Regulation of the pAD1 sex pheromone response in Enterococcus faecalis: Effects of host strain and $\operatorname{tra\mathrm {A}}, \operatorname{tra\mathrm {B}}$, and $\mathrm{C}$ region mutants on expression of an $\mathrm{E}$ region pheromone-inducible lacZ fusion. J. Bacteriol. 172, 26332641.

Weaver, K. E., AND Clewell, D. B. (1991). Control of Enterococcus faecalis sex pheromone cAD1 elaboration: Effects of culture aeration and pAD1 plasmid-encoded determinants. Plasmid, 25, 177-189.

Wirth, R., AN, F. Y., AND Clewell, D. B. (1986). Highly efficient protoplast transformation system for Streptococcus faecalis and a new Escherichia coli-S. faecalis shuttle vector. J. Bacteriol. 165, 831-836.

YAGI, Y., AND CLEWELL, D. B. (1980). Recombinationdeficient mutant of Streptococcus faecalis. $J$. Bacteriol. 143, 966-970.

Youngman, P. J. (1987). Plasmid vectors for recovering and exploiting Tn917 transposition in Bacillus and other gram-positives. In "Plasmids: A Practical Approach" (K. Hardy, Ed.), pp. 79-103. IRL Press, Oxford.

Communicated by Francis L. Macrina 